Elżbieta Umińska-Tytoń

Uniwersytet Łódzki

Katedra Historii Języka Polskiego

\title{
NAZWY OSOBOWE LUDNOŚCI ŻYDOWSKIEJ DZIALOSZYNA W XIX-WIECZNYCH METRYKACH
}

Antroponimia Żydów była dotąd przedmiotem zainteresowania przede wszystkim na terenach wschodniego pogranicza [por. Abramowicz, 2003, 2010; Dacewicz 2008]. Brakuje w literaturze przedmiotu opracowań materiału z pozostałych obszarów Polski. Tym cenniejsze wydają się zachowane zapisy metrykalne z terenu Polski centralnej, z miasteczka Działoszyn.

Działoszyn położony jest w południowej części woj. łódzkiego na Wyżynie Wieluńskiej. Pierwsza informacja o Działoszynie pojawia się w 1411 roku i mówi o istnieniu parafii. W 1412 roku występuje już jako miasto. Od XVI wieku licznie napływają do miasteczka Żydzi, zmuszeni do opuszczenia większych miast, m.in. pobliskiego Wielunia na mocy przywileju „De non tolerandis Judeis” zakazującego dłuższego przebywania ludności żydowskiej w mieście. W rezultacie w XVII i XVIII wieku Działoszyn stał się liczącym skupiskiem Żydów, posiadającym własny kahał czyli gminę. W XVIII wieku większość mieszkańców Działoszyna stanowili już Żydzi. Dzięki nim miasteczko stało się poważnym ośrodkiem handlowo-rzemieślniczym. Mieściły się tu także instytucje kultury żydowskiej - szkoła początkowa dla chłopców (cheder) oraz synagoga. Wśród działoszyńskich kupców znajdowały się też światłe jednostki. Na początku XIX wieku zlikwidowano kahały, a ich funkcje przejęły władze krajowe. W rezultacie od 1808 do 1824 roku akta narodzin, małżeństw i zgonów żydowskich mieszkańców gminy Działoszyn sporządzał urzędnik stanu cywilnego gminy, którym był najpierw burmistrz, później proboszcz [zob. Szczerkowska, 2006]. Przedmiot niniejszej analizy stanowią akta z 10 lat od 1809 do 1818 roku [metryki.genealodzy.pl (dostęp: 10.08.2014)]. 
Metryki, o których mowa, pisane były w języku polskim. Niekiedy świadkowie podpisywali się po hebrajsku. Dopiero od 1867 roku zaczęto sporządzać ksieggi metrykalne w języku rosyjskim. Tekst metryki był standardowy, porównywalny $\mathrm{z}$ analogicznymi zapisami z różnych obszarów kraju. $\mathrm{W}$ akcie urodzenia czytamy'

Roku Tysiącznego Ośmsetnego Dziewiątego Dnia Dziewiętnastego Miesiąca Maja o godzinie drugiey popołudniu Przed Nami Proboszczem Działoszyńskim sprawuiącym Obowiązki Urzędnika Stanu Cywilnego Gminy Działoszyńskiey Powiatu Wielunskiego w Departamencie Kaliskim Stawił się Starozakonny Zelig Abrahamowicz Pakciarz liczący lat Czterdzieści Sześć w Szczytach zamieszkały y okazał Nam Dziecię Płci Żenskiey, które urodziło się w Domu Dworskim pod Numerem Drugim na Dniu Osmym Maja Roku bieżącego, oświadczaiąc, iż iest spłodzone Zniego y Róży z Szaiowiczów Dwadzieścia lat maiącey, iego Małżonki, y że życzeniem iego iest nadać mu Imię Raica. Po uczynieniu powyższego Oświadczenia yOkazaniu Dziecięcia w przytomności Adama Gornego liczącego lat Dwadzieścia y ieden służącego Plebanskiego, tudziesz Moska Dawidowicza Gościnnego Działoszyńskiego, który Rok Czterdziesty skończył. Po Czem Akt ninieyszy urodzenia stawaiącym przeczytawszy podpisany został przez nas samych, Oyca y iednego Swiadka to iest Marka Dawidowicza, a drugi zaś świadek pisać nieumie.

\section{W akcie zawarcia małżeństwa zapisano:}

Roku Tysiącznego Ośmsetnego Dziewiątego Dnia pietnastego Miesiąca Maia.

Przed Nami Proboszczem Parafii Działoszyńskiey, sprawuiącym Obowiązki Urzędnika Stanu Cywilnego Gminy Trębackiey Powiatu Wieluńskiego w Departamencie Kaliskim stawił się starozakonny Salomon AAronowicz maiący lat podług złozoney metryki wydaney od Synagogi Działoszyńskiey Dwadzieścia Siedm będąc Synem Lewka Aarona z Wsi Rychłocic - stawiła się także panna Gitla Corka Joachima Markusa w Assystencyi wspomnionego Oyca swego, licząca podług złożoney metryki od Synagogi Działoszyńskiey wyiętey lat Dwadzieścia Cztery, przy Oycu swym w Wsi Trębaczewie dotąd zostaiąca ktoren iest Kaczmarzem w pomieniony Wsi. - Strony stawaiące żądaią, abyśmy przystapili do Obchodu ułożonego pomiędzy nimi Małżeństwa ktorego Zapowiedzi wyszły Przed Głownemi Drzwiami Naszego Domu Gminnego, to iest: Pierwsza dnia siodmego Miesiąca Maia, Druga dnia czternastego tegoż Miesiąca. Gdy o żadnym tamowaniu rzeczonego Małżeństwa uwiadomieni nie zostaliśmy, a przytomni Oycowie na Obchod ninieyszego Małżeństwa zezwalaią, przychylaiąc się zatym do żądania stron po przeczytaniu Wszystkich wyżey wspomnionych Papierów, y Działu szostego w Tytule Kodeksu Napoleona o Małżeństwie, zapytaliśmy się przyszłego Małżonka y przyszłey Małżonki czyli chcą połączyć się z sobą związkiem Małżeńskim? Na co gdy każde z nich oddzielnie odpowiedziało, iż taka ich iest Wola; ogłaszamy w Jimieniu Prawa, iż Salomon Aaronowicz y Panna Gitla Markusówna połączeni są z sobą węzłem Małżeństwa - Czego spisaliśmy akt w przytomności Mośka Dawidowicza liczącego lat trzydzieści dwa, Jakuba Moskowicza tyleż lat maiącego, y Herszlika Markowicza lat czterdzieści liczącego Mieszkańców działoskich y pokrewnych wspomnionych Aktorow. Akt ninieyszy został stawaiącym tu osobom przeczytany y tak przez nas iako y Osoby tu wyrażone podpisany.

Zachowano ortografię zabytku. Zrezygnowano jedynie z zaznaczania długiego $s$, oddając je jako $s$. 
W metrykach zgonu zapisywano szczegółowe dane osoby zmarłej oraz zgłaszających zgon świadków:

Roku Tysiącznego Ośmsetnego Jedynastego Dnia Siedmnastego Miesiąca Stycznia o godzinie Osmey zrana. Przed Nami Proboszczem Działoszyńskim Urzędnikiem Stanu Cywilnego Gminy Działoszyńskiey w Departamencie Kaliskim Powiecie Wieluńskim stawili się sławetny Jakob Passecki liczący lat pieńdziesiąt Obywatel Działoszyński y Pracowity Karol Pędzel Komornik liczący lat Czterdzieści w Działoszynie zamieszkali y Oświadczyli Nam iż dnia Szesnastego Miesiąca Stycznia Roku bieżącego o godzinie jedynastey w nocy Frameta Medlowiczówna miesięcy dwa maiąca Corka Szai Mendlowicza Maystra Konsztu Krawieckiego w Działoszynie zamieszkałego z Hanką z Moskow Mędlowiczową Małżonkow Umarła w domu pod numerem sto dziewięć. Po Czem Akt Ninieyszy Oswiadczaiącym przeczytany y podpisany został przez Nas Samych bo Oswiadczaiący pisac nie umieią. - Xiądz Woyciech Szymanski proboszcz Działoszyński Urzędnik Stanu Cywilnego.

Przedstawione przykładowo zapisy z ksiag metrykalnych wskazują, że na początku XIX wieku identyfikacja ludności żydowskiej oparta była na imionach. Akta urodzeń dają wgląd w proces nominacji. W latach 1811-1818 zarejestrowano 170 dzieci (54 dziewczynki i 118 chłopców). Nadawano im na ogół jedno imię. Dwa imiona otrzymało zaledwie 6 dziewczynek (Marya Esterka, Chaja Bajla, Esterka Dobra, Bajla Tamer, Ita Ela, Lara Inda) i 19 chłopców (Abraham Berek, Judka Michat, Mędel Salomon, Izaak Jakob, Jakob Mojżesz, Abraham Bier, Dawid Hesse, Izrael Icek, Szlama Dawid, Judka Smol, Judas Mosiek, Ajzyk Jakob, Eliasz Mandel, Jakob Mortke, Eliasz Szaja, Józef Fajbisz, Dawid Icek, Icek Lajzer).

Repertuar imion męskich wykorzystanych w omawianym czasie do nominacji składa się przede wszystkim z imion powstałych na bazie języka hebrajskiego:

a) wywodzących się z Biblii:

Abraham, Abram (hebr. abraham 'ojciec jest wzniosły' lub z akad. 'ojciec kocha'; pierwszy patriarcha, protoplasta narodu żydowskiego)',

Ajzyk, Icek, Izaak (: Icchak, hebr. jicchaq 'Bóg się uśmiechnął’; patriarcha, syn Abrahama),

Boruch (: Baruch, hebr. baruch 'błogosławiony'; syn Neriasza, sekretarz Jeremiasza),

Dawid (hebr. etym. niepewna, związana z rdzeniem dod, 'krewny' lub 'umiłowany'; najmłodszy syn Jessego z Betlejem, namaszczony przez Samuela na króla),

2 Charakterystyka językowa imion za: Abramowicz, 2010, s. 37-124. 
Eliasz (: Elia, hebr. elijjah(u) 'Jahwe jest moim Bogiem'; prorok w Tiszbe w Galaadzie i in.),

Haskiel, Hesse (: Ezechiel, hebr. jechezqe'l 'niech Bóg uczyni mocnym'; kapłan i prorok uprowadzony do Babilonii, autor Księgi Ezechiela), Izrael (hebr. jisra 'el 'Bóg okazał się mocny'; imię Jakuba nadane mu przez Boga po walce),

Jakob, Jankiel, Ankiel (: Jakub, hebr. ja'aqob z sem.ja'aqob 'el 'niech Bóg strzeże'; syn Izaaka i Rebeki),

Joachim (hebr. Jehojaqim 'Bóg wzmocni'),

Jozef (hebr.josep 'niech (Bóg) doda (więcej dzieci)'; syn Izraela, patriarcha), Judka, Judelajb, Judas (: Juda, hebr. jehuda, tradycyjnie łączone z czasownikiem jadah 'wielbić'; syn Jakuba i Lei, eponim rodu pokolenia Judy),

Lajzer (: Eliezer, pol. Łazarz, z hebr. eli'ezer 'Bóg wspomógł'; Damasceńczyk, przyszły spadkobierca Abrama),

Lewek (: Lewi, hebr. lewi 'przyłączony'; syn Jakuba i Lei, eponim rodu kapłańskiego),

Michat (: Mikael, hebr. mika'el 'któż jak Bóg'; ojciec Setura, ojciec Zebadiasza),

Mortke (: Mardocheusz, hebr. mordokaj '(należący do) Marduka'; Beniaminita, krewny i opiekun Estery),

Mosiek, Mojżesz (: Mosze, hebr. mosze, im. teoforyczne, pochodzenia egipskiego z elementem mos 'syn', etymologia popularna 'wydobyty z wody'; wybawiciel Izraela z niewoli egipskiej),

Salomon, Szlama, Zelman, Smul, Smol (: Salomon, hebr. szelomo 'człowiek pokoju'; syn Dawida i Betszeby, urodzony w Jerozolimie następca tronu),

Szaja (: Izajasz, hebr. jeszajah(u) 'Jahwe jest zbawicielem'; syn Amosa, prorok w Judzie),

Szaul (: Saul, hebr. sza 'ul 'wyproszony (u Boga)'; król Edomu, ostatni syn Symeona),

Szymon (hebr. szim ’on '(Bóg) wysłuchał'; drugi syn Jakuba i Lei i in.);

b) zaczerpniętych z Talmudu:

Major, Majer (: Mejer, hebr. meir 'świetlisty, lśniący, świecący').

Pozostałe imiona rozwinęły się w jidisz:

Berek, Bier (: Ber, jid. z niem. Bär 'niedźwiedź', może też łączyć się z niem. imionami Bernhard, Bernold), 
Fajgel, Fajbisz, Fajwisz (: Fajwusz, łac. vivus ‘żywy, żyjący’, kalka imienia Chaim),

Herszlik (: Hirsz, jid. z niem. Hirsch 'jeleń', nawiązanie do Neftalego),

Lipman (jid. z niem. Liebe 'miłość' i Mann 'mężczyzna'),

Mędel, Mendel (: Man, jid. z niem. Mann 'mężczyzna')

Wulf (: Wolf, jid. z niem. Wolf 'wilk', nawiązuje do błogosławieństwa Jakuba, możliwe też pochodzenie od imion z Wolf- Wolfgang, Wolpert, Wolfram i in.).

Nieliczne zostały zapożyczone od Chrześcijan:

Bendent (: Benedykt z łac. benedictus 'błogosławiony'),

Marek (: Marcus 'należący do Marsa - boga wojny, związany z Marsem),

Sender (: Aleksander z gr. alexo 'bronię, wspomagam' i aner 'mąż, mężczyzna').

W zasobie imion żeńskich form biblijnych jest znacznie mniej. Zresztą w samej Biblii imion kobiecych nie jest wiele. Należą tu:

Chewka (: Ewa, hebr. chawwa ‘żyjąca, życiodajna'; imię nadane przez Adama swojej żonie jako 'matce wszelkiego życia'),

Cypra (: Cypora, hebr. cippora 'samica wróbla'; żona Mojżesza, córka kapłana Medianitów),

Dobra (: Debora, hebr. debora 'pszczoła'; piastunka Rebeki),

Ela (: Elżbieta, hebr. eliszeba 'El jest pełnią, szczęściem'; żona Aarona, matka kapłanów),

Esterka (: Estera, hebr. ester 'gwiazda', wg tradycji żydowskiej 'ukryta'; bohaterka Księgi Estery),

Ita (: Judyta, hebr. jehudit 'Judejka, Żydówka'; córka Chetyty Beeriego, żona Ezawa),

Laja (: Leja, hebr. le’a 'silna, dzika krowa'; starsza córka Labana i żona Jakuba),

Marya (hebr./aram. 'wywyższona'; siostra Mojżesza i Aarona),

Rachel, Rochla (: Rachela, hebr. rachel 'owieczka'; młodsza siostra Labana, żona Jakuba, matka Józefa i Beniamina),

Ryfka, Rysla, Resla (: Rebeka, hebr./aram. Ribka 'młócąca'; córka Betuela, siostra Labana, żona Izaaka, matka Ezawa i Jakuba),

Sara (hebr. sara 'księżniczka, pani’; żona Abrahama, matka Izaaka i pokoleń Izraela), 
Tamer, Temerka (: Tamar, hebr. tamar 'palma'; Kananejka, matka Peresa i Zeracha; córka Absaloma).

Nieliczne są imiona hebrajskie postbiblijne:

Chaja (hebr. 'życie', żeński odpowiednik męskiego imienia Chaim), Matka (hebr. malka 'królowa').

Liczniej natomiast przedstawia się zasób imion powstałych na gruncie języka jidisz:

Bajla (: Bejla, jid. z fr. belle 'piękna'),

Bluma (jid. z niem. Blume 'kwiat'),

Frajda (: Frejde, jid. z niem. Freude 'radość'),

Gentel (: Genendel, jid. na bazie imienia Genana / Gnane 'imiennik, imienniczka'),

Gitla (: Guta, jid. na bazie niem. imienia Guda / Guoda - krótka forma od im. z Gud-, Gund- np. Gudrun, Gudula - lub ap. niem. Güte 'dobroć'),

Hindla (: Hinda, jid. z niem. Hindin 'łania', kalka hebr. im. Ciwia),

Lebba (: Liba, jid. z niem. Liebe 'ukochana'),

Majta (: Mejtel, etym. niepewna, może nhebr. mejtal 'krople rosy' lub im. Matylda),

Perla (: Perel, jid. z niem. Perle 'perła', kalka im. hebr. Margolies).

Gdyby uwzględnić wszystkie imiona, jakie znalazły się w metrykach (nie tylko nadane dzieciom urodzonym w omawianym dziesięcioleciu), powyższy wykaz znacznie by się wzbogacił. Zawsze jednak widoczne jest upodobanie działoszyńskich Żydów do określonych imion. Do najczęściej wykorzystywanych imion do nominacji jednoimiennej chłopców należały w omawianym okresie Mosiek (11), Jakob i Herszlik (8), z żeńskich Esterka i Ita (3). Trudno dociec, co decydowało o wyborze imienia. Na podstawie zapisów metrykalnych można jedynie sądzić, że pewne znaczenie miała tradycja rodzinna. Zdają się o tym świadczyć następujące zapisy³:

stawit się Marek Szlamkowicz (...) dac na imię Szlamka... 1814/63u, stawit się Dawid Janklowicz, kupiec wetny (...) zrodzone z Chaji Michatowiczówny (...) dać na imię Michat 1811/80u,

Zachowano pisownię oryginału. Cytaty opatrzono rokiem, z którego pochodzi zapis, numerem zapisu i symbolem u, z, m oznaczającym odpowiednio księgę urodzeń, zgonów i małżeństw. 
stawit się Nachum Abrachamowicz Fabrykant Miodu (...) z niego i Laji Smulowiczowny (...) dać na imię Smul 1811/88u, stawit się Herslik Ickowicz kupiec Wetny (...) na imię Icek 1811/98u, stawili sie Chil Dawidowicz (...) syn Dawida Chylowicza już zmarłego 1811/24m, stawili się Szymon Jakobowicz [syn] Jakoba Szymkowicza 1811/25m.

W rezultacie wcale nierzadkie były zestawienia typu:

Abram Abramowicz 1813/31u, Kopel Koplowicz 1818/199u, Lewek Lewkowicz 1814/7u, 1813/55u, Mosiek Moskowicz 1818/44u, 1818/164u, Smul Smulowicz 1818/149u.

Charakterystyczną cechą wykorzystanego do nominacji imiennictwa jest przewaga form zniekształconych fonetycznie, skróconych oraz pochodnych od pełnych oficjalnych form imion hebrajskich i jidyjskich, zazwyczaj derywowanych sufiksalnie (za pomocą słowiańskich formantów: -ek, -ko, -ka lub jid. -el). Powyższy stan imiennictwa nie jest specyficzny dla Działoszyna z początku XIX wieku. Podobne imiona i ich warianty nadawano zarówno w wiekach wcześniejszych, jak i późniejszych w różnych rejonach kraju [por. Dacewicz, 2008; Abramowicz, 2010] .

Obok imienia dodatkowym elementem identyfikacyjnym Żydów działoszyńskich były formy patronimiczne. Stosowano je zarówno w identyfikacji kobiet, jak i mężczyzn. W większości były formami żywymi, jednopokoleniowymi. Następna generacja tworzyła własne formy na podstawie imienia ojca $\mathrm{z}$ tej generacji, np.

w przytomności Jakoba Bendetowicza Syna Bendeta Moskowicza, a Brata Rodzonego (...) Zelka Bendetowicza 1811/8m,

stawili się Joachim Lewkowicz Mayster kunsztu Krawieckiego (...) wasystencyi oyca Lewka Szlamowicza Handlerza Przekupnika (...) tudziesz Panna Perla Lachmanowiczowna [córka] Lachmana Lewkowicza... 1811/5m, stawili się Szymon Jakubowicz [syn] Jakuba Szymkowicza Handlerza Przekupnika 1811/25m.

Niemal bezwyjątkowo formy patronimiczne identyfikują małe dzieci w aktach zgonów:

4 Zachowano pisownię oryginału. Cytaty opatrzono rokiem, z którego pochodzi zapis, numerem zapisu i symbolem $u, z, m$ oznaczającym odpowiednio księgę urodzeń, zgonów i małżeństw. 
Chaja Joskona liczaca lat dwa córka Joska Aronowicza (...) umarta 1811/56z, Mosiek Abrahamowicz liczacy lat dwa syn Abrahama Moskowicza 1811/24z.

Forma patronimiczna służyła identyfikacji panien i kawalerów, a także kobiet zamężnych, np.:

stawit się Icek Moskowicz kupiec wetny (...) i okazat dziecię (...) z niego i Łaji Lewkowiczowny (...) Małżonki iego 1811/98u.

Kobiety dojrzałe, a zwłaszcza wdowy były nazywane formą pochodną od imienia męża:

Panna Sara Herszlikowiczowna (...) wasystencyi Matki Krawli z Ickowiczow Herszlikowiczowy wdowy 1812/1m,

Esterka Cherszlikowiczowa wdowa liczaca lat 70 Matżonka Złotnika w Dziatoszynie $1811 / 5 z$,

Dwora Herszlikowiczowa liczaca lat 70 Matżonka Herszlika Lewkowicza iuż także zmartego umarła $1811 / 60 \mathrm{z}$,

Rochyma Boruchowa wdowa liczaca lat 60 Matżonka Borucha Jankla Handlarza $1811 / 7 \mathrm{z}$.

Formuła identyfikacyjna kobiet zamężnych stawała się więc trójelementowa. Składały się na nią: imię + forma pochodna od imienia ojca wskazująca na ród + forma pochodna od imienia męża. Bardzo rzadko dodawano jeszcze jakiś element np. wskazujący na wykonywany przez męża zawód np.

Pessa z Godlowiczow Jozefowiczowa Wiernikowa liczaca lat 70 zamieszkata w Działoszynie, córka Godla Dawidowicza i Pessy Markowiczowney, matżonka Jozefa Moskowicza Wiernika Synagogi Działoszyńskiey 1821/72z, Herszlik Zelmowicz (...) syn Zelmana Jozkowicza (...) y Estery z Szlamowiczow Jozkowiczowy 1811/7z.

Patronimy dla każdej osoby tworzono na wzór słowiański: dla mężczyzn za pomocą suf. -owicz \| -ewicz, dla córek -ówna. Formy andronimiczne tworzono przyrostkiem -owa, wyjątkowo -ina:

Bella Manalina liczaca lat 40 Matżonka Manały Mendlowicza 1811/17z.

Nie zawsze jednak występowała forma patronimiczna, niekiedy dodatkowym elementem identyfikującym było imię ojca bez przekształceń słowotwórczych typowych dla patronimików np.: 
Szlama Fajbisz liczacy lat dwa syn Fajbisza Hasklowicza 1811/12z, Jankiel Fajwisz maiacy dni 6 syn Dawida Fajwisza 1811/13z.

Imię w funkcji drugiej części zestawienia nazewniczego dość często się pojawia, np.:

stawit się Szlama Judka kupiec wetny 1811/2u,

Szlama Michatowicz syn Michała Szlamy Handlerza 1811/17z,

stawili się starozakonny Herszlik Littman Piekarz 1811/23z.

W takich przypadkach urzędnik drugie imię traktował jak nazwisko. Świadczą o tym rejestry zamieszczane zwykle na końcu księgi metrykalnej. W akcie urodzenia czytamy: stawit się Mojżesz Tobiasz (...) nadać imię Izrael... 1814/6u. W rejestrze urodzonych zapisano dziecko jako Izrael Moyżesz; w akcie zgonu zapisano, że Abraham Mortka liczacy miesięcy trzy, syn Moska Lewkowicza Muzykanta y Maryi Lewkowiczowny umart 1811/13z. W rejestrze zmarłych zapisano Abraham Mortka, formę Mortka uznając za nazwisko.

Sądzić można, że forma patronimiczna miała przez pewien czas charakter wybitnie urzędowy. W codziennej komunikacji używano zaś imienia ojca jako dodatkowego elementu identyfikacyjnego. Zdaje się o tym świadczyć następujący przykład: (...) w przytomności starozakonnych Beniamina Szaji Pieczętarza (...) tudzież Szlamy Lewkowicza kupca różnych towarów... 1818/208u. Pod aktem ów Szlama Lewkowicz podpisał się jako Lewek Szlamka.

Forma patronimiczna oznaczająca początkowo syna lub córkę nosiciela imienia, od którego powstała, z czasem poszerzała swój zasięg, obejmując całą rodzinę w jednym pokoleniu. W takiej funkcji występowała jako nazwa rodowa kobiety: syn Michała Szlamy (...) y Rochli z Herszlikowiczów Michałowiczowy 1811/18z.

Jednocześnie coraz liczniej pojawiają się zapisy świadczące o przechodzeniu form patronimicznych do następnego pokolenia:

Jankiel Ickowicz (...) syn Szmula Ickowicza 1811/7z, stawit się Herszlik Lewkowicz (...) w asystencyi oyca swego Mocha lewkowicza Kelnera Szynkarza i matki Channy z Ickowiczów lewkowiczowy $1812 / 21 \mathrm{~m}$,

Esterka Abramowiczowna Córka Jakoba Abramowicza 1811/6z, Perla Aaronowiczowna córka Herszlika Dawida Aaronowicza 1820/80z, Herszlik Lewkowicz (...) w asystencyi oyca swego Mocha Lewkowicza $1812 / 21 \mathrm{~m}$. 
W analizowanym czasie w Działoszynie zupełnie sporadycznie zdarzały się dodatkowe określenia identyfikacyjne, występujące obok imienia i patronimikum. Znajdujemy pojedyncze przykłady nazwiska:

a) odmiejscowego:

Ayzyk Wroctawski (...) przekupnik 1811/7z,

b) patronimicznego utworzonego sztucznie członem niem. -berg od nazwy osobowej Gołda:

stawili się starozakonny Tobiasz Syiewicz Goldberg Handlerz (...) w assystencyi brata swego rodzonego Jakoba Szyiewicz Handlerza... 1812/22m,

c) powstałe na wzór polskiego przymiotnika z -in od n.os. Czarny:

(...) Lewek Moskowicz Czarnin Komornik (...) syn Moska Jakobowicza Czarnina 1811/75z,

Pewną osobliwością jest zestawienie trzyelementowe:

stawit się starozakonny Lewek Xiąze Liwerant... 1811/4u, w przytomności Lewka Xiązęcia Liweranta ... 1811/5u.

Następująca po imieniu Lewek forma Ksiaże jest zapewne odpowiednikiem imienia Michat. Według Proroctwa Daniela nosił je anioł opiekuńczy ludu Bożego, zwany Księciem (Dn 10,13,21). Trzeci element Liwerant notowany jest także wśród nazwisk Żydów białostockich i wywodzony z śwn. liuwer 'wierzyciel' [Abramowicz, 2003], w innym miejscu [Abramowicz, 2010] zaś od jid. z ukr. liwerant 'kontrahent, handlarz końmi'. Jednokrotnie poświadczona jest też forma Liwarowski: stawit się starozakonny Lewek Xiąże Liwarowski... 1811/4u. Człon ten regularnie był stosowany w formułach urzędowych, natomiast w podpisie zawsze tylko Lewek Xiaże.

Pozostałe nazwiska obcego pochodzenia, jakie pojawiły się w analizowanych aktach (Zusman, Leybel, Nayman, Fiszel itd.) należą do mieszkańców przybyłych do Działoszyna z innych miejscowości (Żarek, Tuszyna, Piotrkowa Trybunalskiego, Częstochowy).

\section{WNIOSKI}

Z dokonanego przeglądu materiału onomastycznego wynika, że w drugiej dekadzie XIX wieku Żydzi w Działoszynie nie posługiwali się jeszcze nazwiskiem rozumianym jako dziedziczne miano rodowe. Podstawą formuły identyfikacyjnej 
było imię własne oraz imię ojca. W zgromadzonym materiale nie dostrzeżono matronimów.

Imiennictwo Żydów odznacza się przywiązaniem do własnej tradycji. Dzieciom nadawano przede wszystkim imiona rodzime: biblijne, postbiblijne oraz powstałe w języku jidysz. W użyciu (także urzędowym) były formy potoczne imion, nierzadko w wersji spolonizowanej (np. Lewek, Mosiek, Icek itp.). W szerokim zakresie stosowane były żywe formacje patronimiczne, tworzone według wzorów polskich oraz andronimiczne dla kobiet zamężnych. W aktach metrykalnych widoczne są dążenia pisarzy do narzucenia Żydom nazwiska. Obok żywych, jednopokoleniowych patronimów obserwujemy pierwsze przykłady ich dziedziczności. Sporadycznie pojawiają się inne formy identyfikacyjne obok patronimu. Analiza zapisów z późniejszych lat XIX wieku powinna pokazać tempo zmian w zakresie stabilizacji nazwiska żydowskiego. Ta jednak będzie przedmiotem osobnego studium.

\section{ROZWIAZZANIA SKRÓTÓW}

akad. - akadyjski

ap. - apelatywum

aram. - aramejski

etym. - etymologia

fr. $\quad$ - francuski

gr. $\quad-$ grecki

hebr. - hebrajski

im. - imię

jid. $\quad-$ jidyjski łac. - łaciński

n.o. - nazwa osobowa

nhebr. - nowohebrajski

niem. - niemiecki

pol. - polski

sem. - semicki

śwn. - średnio-wysoko-niemiecki

ukr. - ukraiński

\section{BIBLIOGRAFIA}

Abramowicz Zofia, 2010, Antroponimia Żydów białostockich, Białystok.

ABramowicz Zofia, 2003, Słownik etymologiczny nazwisk Żydów białostockich, Białystok.

Brzezina Maria, 1986, Polskie zdrobnienia imion żydowskich w utworach literackich, ,Język Polski”, 66, z. 3-4, s. 269-275.

DAcewicz Leonarda, 2008, Antroponimia Żydów Podlasia w XVI-XVIII wieku, Białystok.

Szczerkowska Teresa, 2006, Działoszyn i okolice, Działoszyn.

metryki.genealodzy.pl (dostęp: 10.08.2014). 